\title{
Circulating levels of monocyte chemoattractant protein-I and interleukin-7 in women who have undergone bilateral salpingo-oophorectomy
}

This article was published in the following Dove Press journal:

Journal of Inflammation Research

27 December 2013

Number of times this article has been viewed

\author{
Anna Tani' \\ Toshiyuki Yasui ${ }^{2}$ \\ Sumika Matsui' \\ Takeshi Kato' \\ Naoko Tsuchiya ${ }^{3}$ \\ Mitsutoshi Yuzurihara ${ }^{3}$ \\ Yoshio Kase ${ }^{3}$ \\ Minoru Irahara' \\ 'Department of Obstetrics and \\ Gynecology, ${ }^{2}$ Department of \\ Reproductive Technology, Institute \\ of Health Biosciences, The University \\ of Tokushima Graduate School, \\ Tokushima, Japan; ${ }^{3}$ Pharmacology \\ Research Department, Tsumura \\ Central Research Institute, \\ Ibaraki, Japan
}

Purpose: The aim of the study reported here was to determine the effect of surgical menopause by bilateral salpingo-oophorectomy (BSO) on circulating levels of cytokines and chemokines related to the pathogenesis of atherosclerosis.

Patients and methods: A total of 110 women were recruited for this study from the outpatient clinic of our facility. We divided the women into three groups: 1) women with a regular menstrual cycle, 2) women in whom less than 5 years had passed since their BSO, and 3) women in whom 5 years or more had passed since their BSO. Concentrations of nine cytokines and chemokines in serum were measured.

Results: The serum monocyte chemoattractant protein-1 (MCP-1) level in women in whom less than 5 years had passed since their BSO was significantly higher than in women with a regular menstrual cycle $(P<0.05)$. There were significant differences in serum interleukin (IL)-7 among the three groups $(P=0.035)$. MCP-1 showed a significant positive correlation $(r=0.320$, $P=0.008$ ) with follicle-stimulating hormone in women with a regular menstrual cycle and in women in whom less than 5 years had passed since their BSO.

Conclusion: A hypoestrogenic state due to BSO induced changes in MCP-1 and IL-7 levels. MCP-1 level showed a significant increase in the early period after BSO, while IL-7 level showed a significant decrease in the late period after BSO.

Keywords: follicle-stimulating hormone, cytokines, chemokines, hypoestrogenism, surgical menopause

\section{Introduction}

Bilateral salpingo-oophorectomy (BSO) causes an abrupt decline in estrogen and acute increase in gonadotropin. The complete elimination of estrogen induces menopausal symptoms in premenopausal women. Previous studies have shown an increase in the rate of coronary heart disease after BSO ${ }^{1,2}$ It has also been demonstrated that the risks of vertebral and hip fractures in women who have undergone BSO increase, since endogenous estrogen has a protective effect on bone health. ${ }^{3}$ A prospective cohort study showed an increase in mortality in women who had undergone BSO before the age of 45 years. $^{4}$

In women, dramatic changes in the endocrine system occur at menopause. The decline in estrogen production results in various degenerative conditions, such as atherosclerosis and osteoporosis. Because the immune and endocrine systems are closely associated, endocrinosenescence may occur simultaneously with immunosenescence. ${ }^{5}$ Several cytokines and chemokines are related to estrogen deficiency and are involved in the pathogenesis, development, and progression of atherosclerosis, cardiovascular 
diseases and osteoporosis. Interleukin (IL)-1, IL-4, IL-6, and tumor necrosis factor-alpha (TNF- $\alpha$ ) have been demonstrated to be mediators of atherosclerosis. ${ }^{6,7}$ It has been reported that the level of circulating IL-6 in postmenopausal women is higher than in premenopausal women, while TNF- $\alpha$ level is lower in postmenopausal women. ${ }^{8}$ We previously reported that levels of IL-8 and monocyte chemoattractant protein-1 (MCP-1), which are responsible for the early stage of atherosclerosis, were increased in women with natural menopause. ${ }^{9}$ However, hormone-replacement therapy (HRT) using estrogen has been widely used to prevent or delay the occurrence of these disorders in postmenopausal women. Serum levels of IL-2 and interferon-gamma (IFN- $\gamma$ ) were decreased after HRT, though the concentration of IL-4 was increased after HRT. ${ }^{10}$ It has also been reported that HRT causes an increase in the level of macrophage colony-stimulating factor. ${ }^{11}$ In human coronary artery endothelial cells, it was demonstrated that MCP-1 production was downregulated by estradiol. ${ }^{12}$ Raloxifene and tamoxifen also inhibited MCP-1 messengerRNA expression. ${ }^{12}$ Moreover, raloxifene therapy decreased the production of IL-1 $\beta$, IL- 6 , IL-12, and TNF- $\alpha{ }^{13}$

In women with surgical menopause, serum levels of IL-4 and IFN- $\gamma$ have been reported to be decreased. ${ }^{14}$ It has been shown that ovariectomy induces an increase in the production of IL-7 and significant increases in the levels of MCP-1 and macrophage inflammatory protein-1 beta (MIP-1 $\beta) .^{15,16}$ However, changes in cytokines and chemokines related to the pathogenesis of atherosclerosis in women who have undergone BSO have not been fully clarified.

The aim of the present study was to determine the effect of estrogen deficiency induced by BSO on circulating levels of cytokines and chemokines related to the pathogenesis of atherosclerosis.

\section{Materials and methods Subjects}

One hundred and ten women (age range 38-81 years) were recruited from the outpatient clinic of the Department of Obstetrics and Gynecology, Tokushima University Hospital, during the period 2007-2012 for this study. Informed consent for study participation was obtained from each woman and the Ethics Committee of Tokushima University Hospital approved the study. Reviews of medical histories, the results of physical examinations, and blood chemistry tests showed that all of the women were in good health. None of the subjects had cardiovascular disease. Subjects suspected of having infectious diseases, inflammatory disorders, malignancy or autoimmune diseases, of being undernourished, or of abusing alcohol or drugs were excluded according to the SENIEUR (SENIor EURopean) protocol. ${ }^{17}$ None of the subjects refused to participate in this research. The weight and height of each of the subjects were measured when they first visited our outpatient clinic.

The women were divided into three groups: 1) women with a regular menstrual cycle and normal follicle-stimulating hormone (FSH) level ( $\mathrm{n}=51), 2)$ women for whom less than 5 years had passed since their BSO $(n=27)$, and 3 ) women for whom 5 years or more had passed since their BSO $(n=32)$.

Venous blood samples were drawn into tubes between 8 am and $10 \mathrm{am}$. Samples obtained were frozen at $-70^{\circ} \mathrm{C}$ until needed for analysis. Serum samples were measured by assay in the same batches.

\section{Measurements of serum cytokine concentrations}

We measured concentrations of IL-1 $\beta$, IL-5, IL-6, IL-7, IL-8, IL-10, TNF- $\alpha$, MIP-1 $\beta$, and MCP-1 - which are involved in the pathogenesis, development, and progression of atherosclerosis $^{18}$ - using a Bio-Plex Pro Human Cytokine 17-plex Assay kit (Bio-Rad Laboratories, Inc, Hercules, CA, USA). Measurements were carried out using a multiplex system. The method has been described in detail previously. ${ }^{19}$ The intra- and inter-assay coefficients of variation (CVs) were $2.0 \%-10.0 \%$ and $3.5 \%-16.1 \%$, respectively. The sensitivity levels were: $1.1 \mathrm{pg} / \mathrm{mL}$ for IL-6 and MIP-1 $\beta, 0.5 \mathrm{pg} / \mathrm{mL}$ for IL-7 and IL-8, $0.8 \mathrm{pg} / \mathrm{mL}$ for IL- $1 \beta$ and IL-5, $0.9 \mathrm{pg} / \mathrm{mL}$ for IL-10, $3.0 \mathrm{pg} / \mathrm{mL}$ for TNF- $\alpha$, and $6.7 \mathrm{pg} / \mathrm{mL}$ for MCP-1.

\section{Measurements of serum concentrations of hormones}

Serum luteinizing hormone (LH) concentration was measured by using a kit (TFB Co, Tokyo, Japan) and serum FSH concentration was measured by immunoradiometric assay using a commercially available kit (TFB Co, Tokyo, Japan). The intra- and inter-assay CVs both ranged from $3 \%$ to $4 \%$. Serum estradiol concentration was measured using a kit (Siemens Healthcare, Los Angeles, CA, USA). Intra- and inter-assay CVs were $4.5 \%-8.0 \%$ and $3.2 \%-12.1 \%$, respectively, and the sensitivity of the assay was $2.5 \mathrm{pg} / \mathrm{mL}$.

\section{Statistical analysis}

Data are presented as medians with 25th to 75 th percentile ranges and averages with standard deviations. Student's $t$-test was used when there was a normal distribution, such as for blood pressure (BP). The Kruskal-Wallis rank test was used to compare differences between multiple groups, and the 
Steel-Dwass adjustment was used for a multiple comparison test. Correlations between cytokines and sex hormones were determined using Spearman's rank order analysis. The chisquare test was used to compare the percentages of smokers in the three groups. Analysis of covariance was used for adjustment by age. A probability of $P<0.05$ was considered significant. Figure 1 show medians, 25 th and 75 th percentiles as boxes, and 10th and 90th percentiles as error bars. All statistical analyses were carried out using Microsoft Excel 2010 (Microsoft Corporation, Redmond, WA, USA) with the add-in software Statcel 3 (OMS, Tokyo, Japan) and SPSS (v 20.0; IBM Corporation, Armonk, NY, USA).

\section{Results}

\section{Characteristics of subjects}

Background characteristics including age; body mass index (BMI); systolic and diastolic BP; levels of $\mathrm{LH}, \mathrm{FSH}$, and estradiol; and percentages of smokers in the three groups are shown in Table 1. There were no significant differences between BMI, BP, and the percentage of smokers among the three groups. There was also no significant difference in age between women with a regular menstrual cycle and women in whom less than 5 years had passed since their BSO. Women in whom more than 5 years had passed since their BSO were significantly older than women in the other two groups.

\section{Serum levels of cytokines and chemokines}

As can be seen in Table 2 and Figure 1, serum IL-7 was significantly different before and after BSO $(P=0.035)$. After adjusting for age, serum IL-7 was not statistically different between the two BSO groups $(P=0.099)$. Serum MCP-1 in women in whom less than 5 years had passed since their BSO was significantly higher than in women with a regular menstrual cycle $(P<0.05)$. There was a nonsignificant increase in serum IL-8 level in women in whom more than 5 years had passed since their BSO. There were no significant differences between the groups in terms of the levels of other cytokines and chemokines.

\section{Correlations of MCP-I with sex hormones}

To clarify whether changes in MCP-1 level are related to hormonal changes, we examined the associations of MCP-1 with hormone levels. Since acute hormonal changes are caused by BSO, we examined the associations of MCP-1 with sex hormones in women with a regular menstrual cycle and women in whom less than 5 years had passed since their BSO. As can be seen in Figure 2, MCP-1 showed a significant positive correlation $(r=0.320, P=0.008)$ with $\mathrm{FSH}$ in women with a regular menstrual cycle and women in whom less than 5 years had passed since their BSO. Since the values of cytokines are not normally distributed, a log scale is used in the figure. MCP-1 also showed a significant positive correlation $(r=0.208, P=0.045)$ with FSH in all subjects. In women in whom more than 5 years had passed since their BSO, MCP-1 and FSH showed no significant correlation. There was no significant correlation between estradiol and MCP-1.

\section{Discussion}

In this study, we found that MCP-1 was significantly increased in women for whom less than 5 years had passed since their BSO and that IL-7 was significantly decreased in women for whom 5 years or more had passed since their BSO.

Estrogen modulates the production of cytokines since immunocompetent cells possess estrogen receptors. ${ }^{20,21}$ The effects of estrogen are mediated by both estrogen $\alpha$ and $\beta$

Table I Clinical characteristics and hormonal data in women with regular menstruation, women in whom less than 5 years had passed since bilateral salpingo-oophorectomy (BSO), and women in whom 5 years or more had passed since their BSO

\begin{tabular}{|c|c|c|c|c|}
\hline Characteristic & No BSO & BSO $<5$ years & BSO $\geq 5$ years & $P$-value ${ }^{a}$ \\
\hline$n$ & 51 & 27 & 32 & \\
\hline Age (years) & $47.0(45.0-49.0)$ & $49.0(46.0-51.0)$ & $58.5^{c}(54.0-63.3)$ & $<0.001$ \\
\hline BMI $\left(\mathrm{kg} / \mathrm{m}^{2}\right)$ & $23.5(21.3-25.0)$ & $25.2(23.3-26.0)$ & $23.4(20.6-24.7)$ & 0.107 \\
\hline Systolic BP (mmHg) & $|28.6 \pm|||$. & $130.9 \pm 10.1$ & $124.6 \pm 16.0$ & \\
\hline Diastolic BP (mmHg) & $77.1 \pm 7.1$ & $79.8 \pm 2.5$ & $73.7 \pm 11.3$ & \\
\hline $\mathrm{LH}(\mathrm{mlU} / \mathrm{mL})$ & $3.5(2.3-5.3)$ & $26.3^{\mathrm{b}}(20.4-36.2)$ & $21.3^{\mathrm{b}}(13.8-27.7)$ & $<0.001$ \\
\hline $\mathrm{FSH}(\mathrm{mlU} / \mathrm{mL})$ & $5.5(4.6-7.2)$ & $79.1^{\mathrm{b}}(66.0-105.1)$ & $86.3^{\mathrm{b}}(71.9-104.6)$ & $<0.001$ \\
\hline Estradiol (pg/mL) & $104.0(7|.0-| 50.0)$ & $21.0^{\mathrm{b}}(12.5-29.0)$ & $12.5^{\mathrm{b}}(12.5-28.0)$ & $<0.001$ \\
\hline Smokers (\%) & 7.4 & 6.3 & 16.7 & \\
\hline
\end{tabular}

Notes: Data expressed as median $(25 \%-75 \%)$ or average \pm standard deviation. ${ }^{a}$ Kruskal-Wallis rank test; ${ }^{b} P<0.0$ I versus women with regular menstruation; ${ }^{c} P<0.0$ I versus women with regular menstruation and women in whom less than 5 years had passed after BSO.

Abbreviations: BMI, body mass index; BP, blood pressure; LH, luteinizing hormone; FSH, follicle-stimulating hormone. 
Table 2 Serum cytokine and chemokine concentrations in women with regular menstruation, women in whom less than 5 years had passed since bilateral salpingo-oophorectomy (BSO), and women in whom 5 years or more had passed since their BSO

\begin{tabular}{|c|c|c|c|c|}
\hline $\begin{array}{l}\text { Cytokine/Chemokine } \\
\text { (pg/mL) }\end{array}$ & No BSO & BSO $<5$ years & BSO $\geq 5$ years & $P$-value ${ }^{a}$ \\
\hline IL-I $\beta$ & $0.40(0.40-0.6 \mathrm{I})$ & $0.40(0.40-0.40)$ & $0.40(0.40-0.40)$ & 0.507 \\
\hline IL-5 & $0.40(0.40-0.40)$ & $0.40(0.40-0.40)$ & $0.40(0.40-0.40)$ & 0.973 \\
\hline IL-6 & $\mathrm{I} .35(0.55-2.6 \mathrm{I})$ & $0.55(0.55-2.18)$ & $0.55(0.55-1.74)$ & 0.128 \\
\hline IL-7 & $4.85(3.36-7.04)$ & $6.57(4.49-9.02)$ & $3.36(2.20-5.57)$ & 0.035 \\
\hline IL-8 & $21.40(5.29-112.45)$ & $18.42(9.08-51.79)$ & $35.35(13.38-104.43)$ & 0.368 \\
\hline IL-10 & $0.45(0.45-0.79)$ & $0.45(0.45-1.16)$ & $0.45(0.45-1.10)$ & 0.861 \\
\hline TNF- $\alpha$ & $1.50(1.50-4.55)$ & $1.50(1.50-6.82)$ & $1.50(1.50-6.54)$ & 0.864 \\
\hline MIP-I $\beta$ & 174.07 (I22.70-246.90) & $150.46(|28.60-236.4|)$ & I7I.29 (I I $2.1 \mid-257.48)$ & 0.824 \\
\hline MCP-I & $31.35(23.03-42.58)$ & $42.98^{\mathrm{b}}(29.30-55.6 \mathrm{I})$ & 34.30 (25.79-49.59) & 0.085 \\
\hline
\end{tabular}

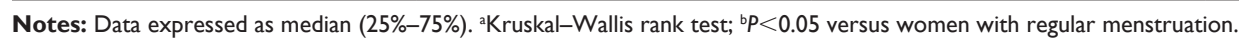

Abbreviations: IL, interleukin; MCP-I, monocyte chemoattractant protein-I; MIP-I $\beta$, macrophage inflammatory protein-I beta; TNF- $\alpha$, tumor necrosis factor-alpha.

receptors, ${ }^{22}$ which have been found in a variety of murine and human immune cells, including thymocytes, monocytes, B cells, and T cells. ${ }^{20,23}$ It has been reported that subjects with estrogen deficiency are susceptible to various kinds of immunologic impairments. ${ }^{24}$ The immune and endocrine systems are closely associated, and endocrine senescence may therefore occur simultaneously with immunosenescence. Since the immune system is also involved in the pathogenesis, development, and progression of atherosclerosis, the decline of estrogen production in women at menopause results in various degenerative conditions, including atherosclerosis. HRT is widely used to prevent or delay the occurrence of disorders in menopausal women by improving the immune system. It has been demonstrated that HRT decreases the production of IL-1, IL-6, IL-12, and TNF- $\alpha .{ }^{25-27}$ Estrogen influences the complex metabolism of lipoproteins in the arterial wall, helping to impede the formation of the atherosclerotic plaque. While estrogen alters endothelial function, vascular reactivity, and fibrinolysis, these changes are also seen with reduction of low-density lipoprotein cholesterol, which may partly reflect the altered concentration of plasma lipoproteins induced by estrogen. ${ }^{28}$

MCP-1 has an important role as a key modulator of atherogenesis since it is involved in the change from rolling to adhesion of monocytes in vessels in the early stage of atherosclerosis and the recruitment of monocytes to the site of active inflammation. ${ }^{29,30}$ We have previously demonstrated high MCP-1 levels in the perimenopausal period and postmenopause. ${ }^{9}$ In the present study, we found that MCP-1 level was increased in women in whom less than 5 years had passed since their BSO. Therefore, a hypoestrogenic state due to BSO induced change in MCP-1 level, which plays an important role in the early onset of atherosclerosis, in the first few years following BSO. It has been reported that transdermal estrogen therapy significantly decreases MCP- $1,{ }^{31}$ suggesting that estrogen is closely associated with the action of MCP-1.
MCP-1

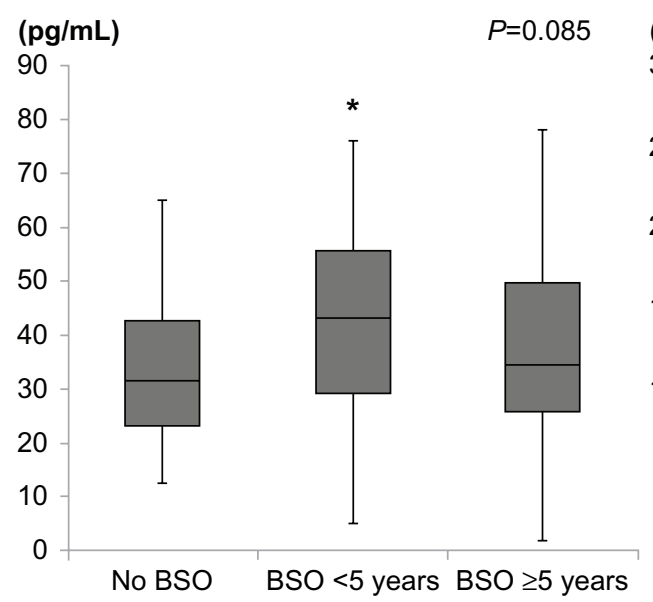

\section{IL-7}

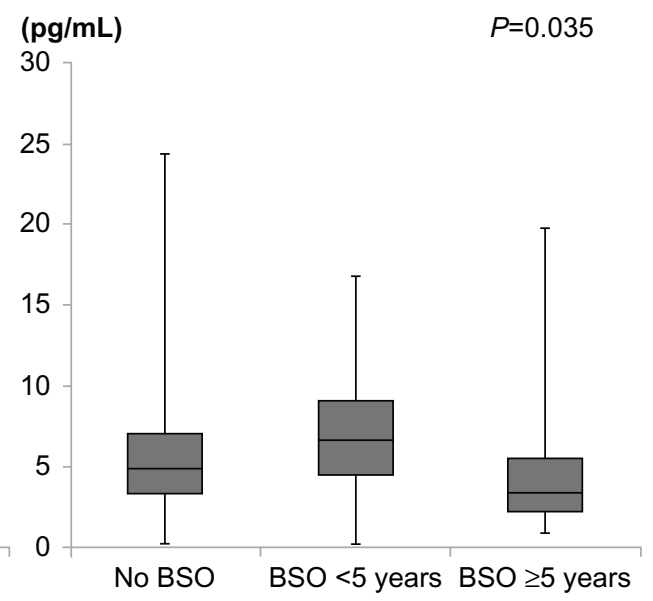

Figure I Monocyte chemoattractant protein-I (MCP-I) and interleukin-7 (IL-7) levels in women before and after bilateral salpingo-oophorectomy (BSO). Note: $* P<0.05$ versus women with regular menstruation. 


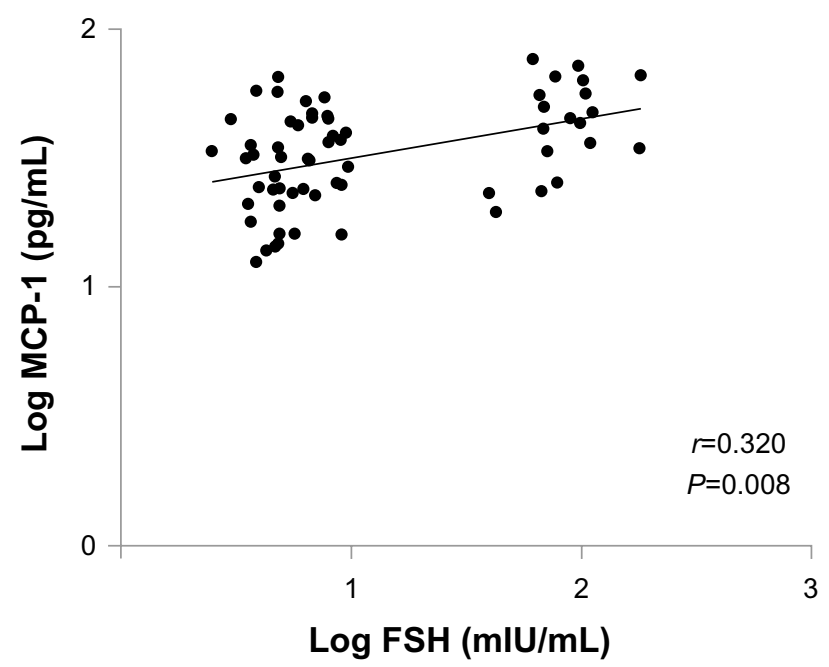

Figure 2 Correlations of monocyte chemoattractant protein-I (MCP-I) level with follicle-stimulating hormone (FSH) level in women with regular menstruation and women in whom less than 5 years had passed since their bilateral salpingooophorectomy.

However, we showed that MCP-1 has a significant positive correlation with FSH but not with estradiol. In our previous study, we showed that there was a significant positive correlation between MCP-1 and FSH in serum in women during the menopausal transition. ${ }^{9} \mathrm{MCP}-1$ might be more sensitive to an increase in FSH than to a decrease in estradiol. FSH is elevated during the menopausal transition but not after menopause. Thus, early atherosclerosis change may occur before abrupt decline of estrogen. Recently, it was reported that the FSH receptor is expressed on the surfaces of tumor blood vessels and that a high FSH level is associated with acceleration of the progression of subclinical atherosclerosis in midlife women. ${ }^{32,33}$ Therefore, a close relationship between MCP-1 and FSH may be important for the progression of atherosclerosis.

It has been reported that IL-7 is involved in the first step of adhesion of leukocytes to endothelial cells and that its receptor is present in human microvascular endothelial cells. ${ }^{34,35}$ IL-7 is also over-secreted by omental adipose tissue in obese subjects. ${ }^{36}$ Therefore, IL-7 may have a potential role in endothelial cells and adipose tissue, in relation to estrogen deficiency. Several authors have shown that the expression of IL-7 messenger RNA declines with aging. ${ }^{37,38}$ Moreover, we have previously reported that circulating IL-7 level was decreased in women for whom more than 5 years had passed since menopause, ${ }^{9}$ and, in the present study, IL-7 showed a significant decrease in the late period after BSO. The reason for our results showing a low IL-7 level in women with estrogen deficiency for a long time is not clear.
In ovariectomized rats, circulating levels of IL-6, TNF- $\alpha$, and IL- $1 \beta$ were found to be increased significantly. ${ }^{39-41}$ However, to our knowledge, there have been few reports on changes of cytokines in surgically menopausal women. Serum levels of IL- 4 and IFN- $\gamma$ have been reported to be decreased in women with surgical menopause. ${ }^{14}$ We did not find any significant differences in serum levels of IL-1 $\beta$, IL-5, IL-6, IL-8, IL-10, MIP-1 $\beta$, or TNF- $\alpha$ among the three groups. We have previously reported that an increase in serum IL-8 after menopause and a negative correlation with FSH in the postmenopausal stage..$^{9}$ In the present study, a nonsignificantly high level of IL-8 was found in women in whom 5 years or more had passed following their BSO. A significant change in IL-8 level may persist for a long period after estrogen deficiency. The discrepancy in the results between those women with natural menopause and those with surgical menopause may be due to acute changes in levels of estradiol and gonadotropin. Although the gradual changes in estradiol and FSH in naturally menopausal women can result in recovery of their immune function via a feedback mechanism, the acute decrease in estradiol and the acute increase in FSH in surgically menopausal women may influence immune function. Moreover, the discrepancy in the results may be due to differences in the methods used for the measurement of cytokines.

Administration of a gonadotropin-releasing hormone $(\mathrm{GnRH})$ agonist as well as BSO induces changes in cytokines and chemokines due to acute sex hormone change. We have previously showed that a hypoestrogenic state in women with myoma uteri during GnRH-agonist treatment induced increases in circulating levels of MCP-1 and MIP-1 $\beta .^{42}$ In women with ovarian endometriomas, serum IL-6 decreased after treatment with a GnRH agonist. ${ }^{43} \mathrm{GnRH}$-agonist treatment leads to a flare-up phenomenon of gonadotropin and thereafter suppresses the secretion of gonadotropin by downregulation of the GnRH receptor. The differences in gonadotropin levels induced by GnRH-agonist treatment and BSO may cause the different changes in cytokines and chemokines.

\section{Limitations}

Our results were based on a cross-sectional study, and a future longitudinal study should be carried out. We measured circulating levels of cytokines and chemokines, which were the sum total of cytokines produced in various tissues. Since the sources of cytokines and chemokines and sites at which these cytokines act are different, it might be necessary to investigate the local expression of MCP-1 in 
endothelial cells. Moreover, the groups were not homogenous since the women in whom more than 5 years had passed following their BSO were significantly older than the women in the other two groups.

\section{Conclusion}

In this study, a hypoestrogenic state due to BSO induced changes in MCP-1 and IL-7. MCP-1 showed a significant increase in the early period after BSO and IL-7 showed a significant decrease in the late period following BSO. We also showed that change in MCP-1 is sensitive to an acute increase in FSH after BSO.

\section{Acknowledgment}

This study was supported in part by a Grant-in-Aid for Scientific Research (C: 22591857) from the Japan Society for the Promotion of Science.

\section{Disclosure}

The authors report no conflicts of interest in this work.

\section{References}

1. Parker WH, Broder MS, Chang E, et al. Ovarian conservation at the time of hysterectomy and long-term health outcomes in the nurses' health study. Obstet Gynecol. 2009;113(5):1027-1037.

2. Howard BV, Kuller L, Langer R, et al; Women's Health Initiative. Risk of cardiovascular disease by hysterectomy status, with and without oophorectomy: the Women's Health Initiative Observational Study. Circulation. 2005;111(12):1462-1470.

3. Melton LJ 3rd, Crowson CS, Malkasian GD, O'Fallon WM. Fracture risk following bilateral oophorectomy. J Clin Epidemiol. 1996;49(10):1111-1115.

4. Rocca WA, Grossardt BR, de Andrade M, Malkasian GD, Melton LJ 3rd. Survival patterns after oophorectomy in premenopausal women: a population-based cohort study. Lancet Oncol. 2006;7(10): 821-828.

5. Straub RH, Konecna L, Hrach S, et al. Serum dehydroepiandrosterone (DHEA) and DHEA sulfate are negatively correlated with serum interleukin-6 (IL-6), and DHEA inhibits IL-6 secretion from mononuclear cells in man in vitro: possible link between endocrinosenescence and immunosenescence. J Clin Endocrinol Metab. 1998;83(6):2012-2017.

6. de Bont N, Netea MG, Rovers C, et al. LPS-induced cytokine production and expression of LPS-receptors by peripheral blood mononuclear cells of patients with familial hypercholesterolemia and the effect of HMGCoA reductase inhibitors. Atherosclerosis. 1998;139(1):147-152.

7. Barks JL, McQuillan JJ, Iademarco MF. TNF-alpha and IL-4 synergistically increase vascular cell adhesion molecule-1 expression in cultured vascular smooth muscle cells. J Immunol. 1997;159(9):4532-4538.

8. Cioffi M, Esposito K, Vietri MT, et al. Cytokine pattern in postmenopause. Maturitas. 2002;41(3):187-192.

9. Tani A, Yasui T, Matsui S, et al. Different circulating levels of monocyte chemoattractant protein-1 and interleukin-8 during the menopausal transition. Cytokine. 2013;62(1):86-90.

10. Xia X, Zhang S, Yu Y, et al. Effects of estrogen replacement therapy on estrogen receptor expression and immunoregulatory cytokine secretion in surgically induced menopausal women. J Reprod Immunol. 2009;81(1):89-96.
11. Kamada M, Irahara M, Maegawa M, et al. Postmenopausal changes in serum cytokine levels and hormone replacement therapy. Am J Obstet Gynecol. 2001;184(3):309-314.

12. Seli E, Pehlivan T, Selam B, Garcia-Velasco JA, Arici A. Estradiol down-regulates MCP-1 expression in human coronary artery endothelial cells. Fertil Steril. 2002;77(3):542-547.

13. Kasai Y, Maegawa M, Yamamoto S, et al. Effects of raloxifene on the production of cytokines in stimulated whole blood in ex vivo and in vitro studies. J Med Invest. 2011;58(1-2):110-117.

14. Kumru S, Godekmerdan A, Yilmaz B. Immune effects of surgical menopause and estrogen replacement therapy in peri-menopausal women. J Reprod Immunol. 2004;63(1):31-38.

15. Weitzmann MN, Roggia C, Toraldo G, Weitzmann L, Pacifici R. Increased production of IL-7 uncouples bone formation from bone resorption during estrogen deficiency. J Clin Invest. 2002;110(11): 1643-1650.

16. Abu-Taha M, Rius C, Hermenegilbo C, et al. Menopause and ovariectomy cause a low grade of systemic inflammation that may be prevented by chronic treatment with low doses of estrogen or losartan. J Immunol. 2009;183(2):1393-1402.

17. Ligthart GJ, Corberand JX, Fournier C, et al. Admission criteria for immunogerontological studies in man: the SENIEUR protocol. Mech Ageing Dev. 1984;28(1):47-55.

18. Tedgui A, Mallat Z. Cytokines in atherosclerosis: pathogenic and regulatory pathways. Physiol Rev. 2006;86(2):515-581.

19. Yasui T, Maegawa M, Tomita J, et al. Changes in serum cytokine concentrations during the menopausal transition. Maturitas. 2007;56(4): 396-403.

20. Suenaga R, Evans MJ, Mitamura K, Rider V, Abdou NI. Peripheral blood T cells and monocytes and B cell lines derived from patients with lupus express estrogen receptor transcripts similar to those of normal cells. J Rheumatol. 1998;25(7):1305-1312.

21. Straub RH. The complex role of estrogens in inflammation. Endocrine Rev. 2007;28(5):521-574.

22. White R, Parker MG. Molecular mechanisms of steroid hormone action. Endocr Relat Cancer. 1998;5:1-14.

23. Kohen F, Abel L, Sharp A, et al. Estrogen-receptor expression and function in thymocytes in relation to gender and age. Dev Immunol. 1998;5(4):277-285.

24. Albrecht AE, Hartmann BW, Scholten C, Huber JC, Kalinowska W, Zielinski CC. Effect of estrogen replacement therapy on natural killer cell activity in postmenopausal women. Maturitas. 1996;25(3): 217-222.

25. Ralston SH, Russsell RG, Gowen M. Estrogen inhibits release of tumor necrosis factor from peripheral blood mononuclear cells in postmenopausal women. J Bone Miner Res. 1991;5(9):983-988.

26. Rogers A, Eastell R. The effect of 17beta-estradiol on production of cytokines in cultures of peripheral blood. Bone. 2001;29(1):30-34.

27. Matalka KZ. The effect of estradiol, but not progesterone, on the production of cytokines in stimulated whole blood, is concentrationdependent. Neuro Endocrinol Lett. 2003;24(3-4):185-191.

28. Newnham HH. Oestrogens and atherosclerotic vascular disease - lipid factors. Baillieres Clin Endocrinol Metab. 1993;7(1):61-93.

29. Gerszten RE, Garcia-Zepeda EA, Lim YC, et al. MCP-1 and IL-8 trigger firm adhesion of monocytes to vascular endothelium under flow conditions. Nature. 1999;398(6729):718-723.

30. Krishnaswamy G, Kelley J, Yerra L, Smith JK, Chi DS. Human endothelium as a source of multifunctional cytokines: molecular regulation and possible role in human disease. J Interferon Cytokine Res. 1999;19(2):91-104.

31. Yasui T, Saijo A, Uemura H, et al. Effects of oral and transdermal estrogen therapies on circulating cytokines and chemokines in postmenopausal women with hysterectomy. Eur J Endocrinol. 2009;161(2):267-273.

32. Radu A, Pichon C, Camparo P, et al. Expression of folliclestimulating hormone receptor in tumor blood vessels. $N$ Engl J Med. 2010;363(17):1621-1630. 
33. El Khoudary SR, Wildman RP, Matthews K, Thurston RC, Bromberger JT, Sutton-Tyrrell K. Endogenous sex hormones impact the progression of subclinical atherosclerosis in women during the menopausal transition. Atherosclerosis. 2012;225(1):180-186.

34. Ariel A, Hershkoviz R, Cahalon L, et al. Induction of T cell adhesion to extracellular matrix or endothelial cell ligands by soluble or matrixbound interleukin-7. Eur J Immunol. 1997;27(10):2562-2570.

35. Duś D, Krawczenko A, Załecki P, et al. IL-7 receptor is present on human microvascular endothelial cells. Immunol Lett. 2003;68(2):163-168.

36. Maury E, Ehala-Aleksejev K, Guiot Y, Detry R, Vandenhooft A, Brichard SM. Adipokines oversecreted by omental adipose tissue in human obesity. Am J Physiol Endocrinol Metab. 2007;293(3): E656-E665.

37. Andrew D, Aspinall R. Age-associated thymic atrophy is linked to a decline in IL-7 production. Exp Gerontol. 2002;37(2-3):455-463.

38. Linton PJ, Dorshkind K. Age-related changes in lymphocyte development and function. Nat Immunol. 2004;5(2):133-139.
39. Zhu X, Luo J, Chen X, et al. Expression characteristic and significance of interleukin-6, nuclear factor kappa beta, and bone formation markers in rat models of osteoporosis. Transl Res. 2008;152(1): 18-23.

40. Chen BL, Li YQ, Xie DH, He QL, Yang XX. Blocking TNF- $\alpha$ with infliximab alleviates ovariectomy induced mechanical and thermal hyperalgesia in rats. Neurol Sci. 2012;33(3):527-533.

41. Percegoni N, Ferreira AC, Rodrigues CF, et al. Profile of serum IL1beta and IL-10 shortly after ovariectomy and estradiol replacement in rats. Horm Metab Res. 2009;41(1):50-54.

42. Matsui S, Yasui T, Uemura H, et al. Induction of circulating monocyte chemoattractant protein-1 in women with gonadotropin-releasing hormone agonist. J Reprod Immunol. 2011;90(2):227-234.

43. Iwabe T, Harada T, Sakamoto Y, et al. Gonadotropin-releasing hormone agonist treatment reduced serum interleukin- 6 concentrations in patients with ovarian endometriomas. Fertil Steril. 2003;80(2) 300-304.

\section{Publish your work in this journal}

The Journal of Inflammation Research is an international, peer-reviewed open-access journal that welcomes laboratory and clinical findings on the molecular basis, cell biology and pharmacology of inflammation including original research, reviews, symposium reports, hypothesis formation and commentaries on: acute/chronic inflammation; mediators of inflamma-

\section{Dovepress}

tion; cellular processes; molecular mechanisms; pharmacology and novel anti-inflammatory drugs; clinical conditions involving inflammation. The manuscript management system is completely online and includes a very quick and fair peer-review system. Visit http://www.dovepress.com/ testimonials.php to read real quotes from published authors.

Submit your manuscript here: http://www.dovepress.com/journal-of-inflammation-research-journal 